\title{
The C-terminal region of Ge-1 presents conserved structural features required for P-body localization
}

\author{
MARTIN JINEK, ${ }^{1,3}$ ANA EULALIO, ${ }^{2}$ ANDREAS LINGEL, ${ }^{2,4}$ SIGRUN HELMS, ${ }^{2}$ ELENA CONTI, ${ }^{1}$ \\ and ELISA IZAURRALDE ${ }^{2}$ \\ ${ }^{1}$ Department of Structural Cell Biology, Max Planck Institute of Biochemistry, D-82152 Martinsried, Germany \\ ${ }^{2}$ Department of Biochemistry, Max Planck Institute for Developmental Biology, D-72076 Tübingen, Germany
}

\begin{abstract}
The removal of the $5^{\prime}$ cap structure by the DCP1-DCP2 decapping complex irreversibly commits eukaryotic mRNAs to degradation. In human cells, the interaction between DCP1 and DCP2 is bridged by the Ge-1 protein. Ge-1 contains an Nterminal WD40-repeat domain connected by a low-complexity region to a conserved C-terminal domain. It was reported that the C-terminal domain interacts with DCP2 and mediates Ge-1 oligomerization and P-body localization. To understand the molecular basis for these functions, we determined the three-dimensional crystal structure of the most conserved region of the Drosophila melanogaster Ge-1 C-terminal domain. The region adopts an all $\alpha$-helical fold related to ARM- and HEAT-repeat proteins. Using structure-based mutants we identified an invariant surface residue affecting P-body localization. The conservation of critical surface and structural residues suggests that the $\mathrm{C}$-terminal region adopts a similar fold with conserved functions in all members of the Ge-1 protein family.
\end{abstract}

Keywords: decapping; EDC4; Hedls; mRNA decay; P-bodies

\section{INTRODUCTION}

mRNA degradation plays a central role in regulating gene expression. In eukaryotes this process is normally initiated by a gradual shortening of the poly(A) tail by deadenylation, followed by exonucleolytic digestion from the $3^{\prime}$ end by the exosome and its cofactors (Parker and Song 2004; Houseley et al. 2006). Alternatively, decay can also occur by the removal of the $5^{\prime}$ cap structure by the decapping enzyme DCP2 and subsequent 5' -to-3' exonucleolytic degradation by XRN1 (Parker and Song 2004; Bail and Kiledjian 2006; Simon et al. 2006).

Present addresses: ${ }^{3}$ Department of Molecular Cell Biology and Howard Hughes Medical Institute, University of California at Berkeley, 731 Stanley Hall, Berkeley, CA 94720-3220, USA; ${ }^{4}$ Department of Protein Engineering, Genentech, Inc., South San Francisco, CA 94080, USA.

Reprint requests to: Elena Conti, Department of Structural Cell Biology, Max Planck Institute of Biochemistry, Am Klopferspitz 18, D82152 Martinsried, Germany; e-mail: conti@biochem.mpg.de; or Elisa Izaurralde, Department of Biochemistry, Max Planck Institute for Developmental Biology, Spemannstrasse 35, D-72076 Tübingen, Germany; e-mail: elisa.izaurralde@tuebingen.mpg.de; fax: 49-70-71-601-1353.

Article published online ahead of print. Article and publication date are at http://www.rnajournal.org/cgi/doi/10.1261/rna.1222908.
Decapping is an irreversible step in the decay pathway of bulk mRNA and is therefore tightly regulated. The decapping enzyme DCP2 requires additional proteins for full activity and/or stability. These proteins are generically termed decapping co-activators (or enhancers of decapping, EDCs), although they may activate decapping by different mechanisms (Parker and Song 2004; Bail and Kiledjian 2006; Simon et al. 2006). In Saccharomyces cerevisiae, proteins that activate decapping include DCP1, the enhancer of decapping-1-3 (EDC1-3), the heptameric LSm1-7 complex, the DExH/D-box RNA helicase 1 (Dhh1, $\mathrm{RCK} / \mathrm{p} 54$ in mammals or Me31B in Drosophila melanogaster), and Pat1 (Parker and Song 2004; Bail and Kiledjian 2006; Simon et al. 2006). S. cerevisiae DCP1 interacts directly with DCP2 and is required for decapping in vivo (She et al. 2004, 2006, 2008).

In human cells, the interaction between DCP1 and DCP2 appears to be mediated by the decapping activator $\mathrm{Ge}-1$ (also known as EDC4 or Hedls, $\underline{H}$ uman enhancer of decapping large subunit; Fenger-Grøn et al. 2005; Yu et al. 2005), which has no ortholog in S. cerevisiae. Ge-1, DCP1, and DCP2 are part of a multimeric protein complex, which also includes EDC3 and the RNA helicase RCK/ 
p54 (Fenger-Grøn et al. 2005). All of these proteins colocalize in discrete cytoplasmic foci known as P-bodies (Eulalio et al. 2007a; Parker and Sheth 2007). Similarly, in Arabidopsis thaliana DCP1 and DCP2 interact with Varicose (the $A$. thaliana Ge-1 ortholog), suggesting that the role of Ge-1 as a physical bridge between DCP1 and DCP2 is conserved in multicellular organisms (Xu et al. 2006).

The Ge-1 protein family is characterized by an $\mathrm{N}$ terminal seven-bladed $\beta$-propeller fold and a conserved C-terminal domain. The N-terminal and C-terminal globular domains are separated by a low-complexity region rich in serines (Ser-rich linker), which is thought to provide a flexible linker (Deyholos et al. 2003; Fenger-Grøn et al. 2005; Yu et al. 2005; Xu et al. 2006, Eulalio et al. 2007c). In Homo. sapiens, D. melanogaster, and A. thaliana, the Ge-1 proteins localize to P-bodies and are required for P-body integrity (Fenger-Grøn et al. 2005; Yu et al. 2005; Xu et al. 2006; Eulalio et al. 2007 b,c). Analysis of the subcellular localization of $\mathrm{Ge}-1$ protein domains (N-terminal $\beta$ propeller domain, the Ser-rich linker, and the C-terminal domain) indicated that the C-terminal domain is necessary and sufficient for P-body targeting (Yu et al. 2005; Xu et al. 2006; Eulalio et al. 2007c). In plants, this domain also mediates DCP1 and DCP2 interaction, as well as selfassociation (Xu et al. 2006). To shed light on the molecular basis for Ge-1 functions, we determined the threedimensional structure of the highly conserved C-terminal region of $D$. melanogaster $\mathrm{Ge}-1$ and identified an invariant surface residue that is crucial for P-body localization.

\section{RESULTS}

\section{Crystal structure of the highly conserved C-terminal region of Ge-1}

Human Ge-1 localizes to P-bodies via a C-terminal domain encompassed by residues 1020-1401, which correspond to residues 944-1354 in the D. melanogaster ortholog (Fig. 1A; $\mathrm{Yu}$ et al. 2005; Eulalio et al. 2007c). The very C-terminal end of this domain (residues 1220-1354, referred to as Ge-1 $1_{C}$ ) is highly conserved across species (Fig. 1A, dark blue). Attempts to crystallize the entire C-terminal domain of D. melanogaster Ge-1 failed, despite the fact that this domain could be successfully expressed and purified. Welldiffracting crystals were, however, obtained with a shorter construct encompassing the C-terminal, highly conserved region of Ge-1 (Ge-1C; residues 1220-1354).

The structure was solved using single-wavelength anomalous dispersion (SAD) data collected from a crystal of selenomethionine-substituted protein. There are two molecules in the crystal asymmetric unit (molecules A and B), related by a noncrystallographic dyad axis. The final model is refined at a resolution of $1.9 \AA$, with final free- $R$ and working- $R$ factors of $25.4 \%$ and $21.1 \%$, respectively, and excellent stereochemistry (Table 1). In molecule A, essentially
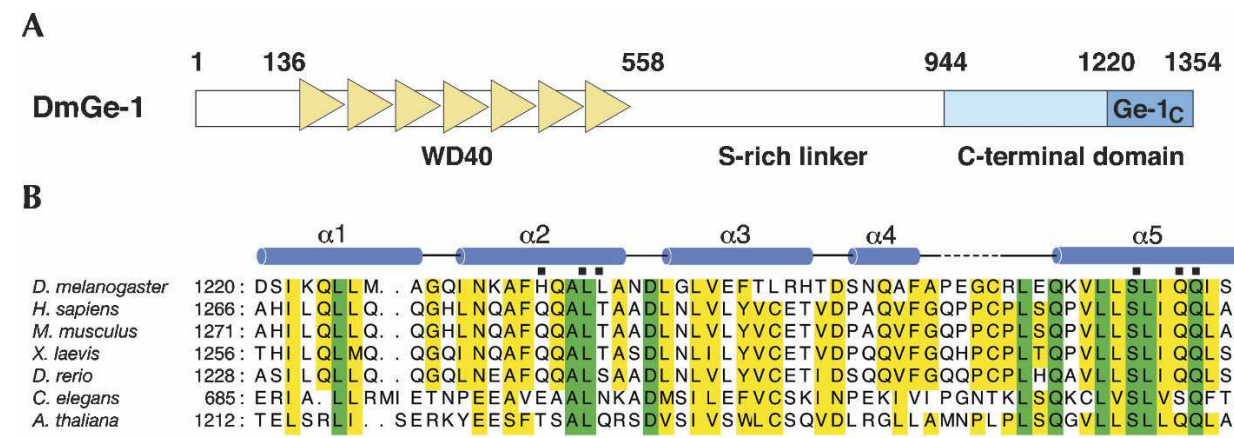

D. melanogaster
H. sapiens
M. musculus
X. laevis
D. rerio
C. elegans
A. thaliana

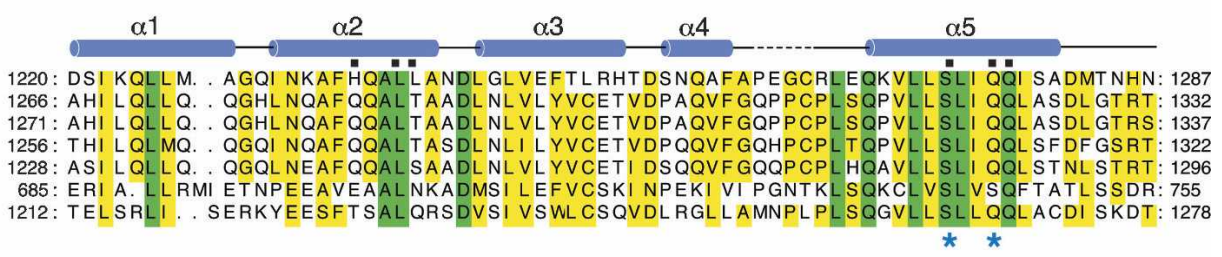

$\alpha 6$

$\alpha 7$

$\alpha 8$

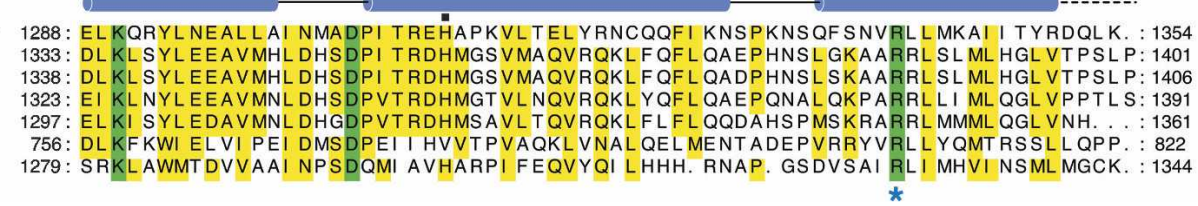

FIGURE 1. Domain organization of Ge-1 and structure-based sequence alignment of the Ge-1 C-terminal region. $(A)$ Schematic diagram of the domain organization of Ge-1. The N-terminal WD40-repeat domain is highlighted in light yellow. The C-terminal domain is highlighted in blue and the highly conserved C-terminal region $\left(\mathrm{Ge}-1_{\mathrm{C}}\right)$, is colored in dark blue. The numbering corresponds to the D. melanogaster Ge-1 ortholog (CG6181, SwissProt entry Q9VKK1). (B) A multiple sequence alignment of Ge-1 orthologs from D. melanogaster, H. sapiens, Mus musculus, Xenopus laevis, Danio rerio, C. elegans, and A. thaliana. Invariant residues are highlighted in green while significantly conserved residues $(>65 \%$ conservation) are highlighted in yellow. Asterisks indicate residues mutagenized in this study; dots indicate residues involved in the dimerization interface. 
TABLE 1. Data collection and phasing statistics

\begin{tabular}{|c|c|c|}
\hline & Native & SeMet peak \\
\hline X-ray source & SLS & SLS \\
\hline Space group & $P 2_{1} 2_{1} 2_{1}$ & $P 2{ }_{1} 2{ }_{1} 2_{1}$ \\
\hline$a, b, c(\AA)$ & $38.2,65.9,103.8$ & $38.4,66.2,103.5$ \\
\hline$\alpha, \beta, \gamma\left(^{\circ}\right)$ & $90,90,90$ & $90,90,90$ \\
\hline Wavelength $(\AA)$ & 0.97897 & 0.97897 \\
\hline Resolution $(\AA)^{\mathrm{a}}$ & $55.6-1.9(2.0-1.9)$ & $50-2.7(2.85-2.7)$ \\
\hline Unique reflections & 20,948 & 15,474 \\
\hline Completeness $(\%)^{\mathrm{a}}$ & $98.0(88.8)$ & $99.9(99.9)$ \\
\hline Multiplicity ${ }^{\mathrm{a}}$ & $4.1(3.2)$ & $2.3(2.3)$ \\
\hline$I / \sigma^{\mathrm{a}}$ & $15.9(2.5)$ & $7.8(2.0)$ \\
\hline$R_{\text {sym }}(\%)^{\mathrm{a}}$ & $7.0(43.9)$ & $7.8(28.9)$ \\
\hline FOM (acentric) $)^{b}$ & & 0.42 \\
\hline Phasing power (acentric) ${ }^{\mathrm{b}}$ & & 1.44 \\
\hline FOM after solvent flipping ${ }^{\mathrm{b}}$ & & 0.86 \\
\hline \multicolumn{3}{|c|}{ Refinement and model statistics } \\
\hline$R_{\text {free }}(\%)$ & 25.4 & \\
\hline$R_{\text {work }}(\%)$ & 21.1 & \\
\hline \multicolumn{3}{|l|}{$\begin{array}{l}\text { Ramachandran } \phi, \psi \text { angles } \\
\text { (non Pro/Gly residues) }\end{array}$} \\
\hline Most favored & $95.0 \%$ & \\
\hline Additionally allowed & $5.0 \%$ & \\
\hline RMSD bond lengths $(\AA)$ & 0.017 & \\
\hline RMSD bond angles $\left(^{\circ}\right)$ & 1.5 & \\
\hline Protein residues & 259 & \\
\hline Water molecules & 160 & \\
\hline
\end{tabular}

${ }^{a}$ Values in parentheses correspond to the highest resolution shell.

${ }^{\mathrm{b}}$ As determined with SHARP. (FOM) figure of merit. among others, the ARM-repeat protein importin- $\alpha$ (Conti and Kuriyan 2000), the 14-3-3 protein (Rittinger et al. 1999), and the HEAT repeat protein eIF4GII (Fig. 2B; Marcotrigiano et al. 2001). These proteins superpose with root-mean-square deviation (RMSD) of $3.2 \AA$ over $116 \alpha$-carbon atoms $\left(\mathrm{C}_{\alpha}\right)$, of $3.3 \AA$ over $94 \mathrm{C}_{\alpha}$, and of $3.6 \AA$ over 116 $\mathrm{C}_{\alpha}$, respectively. The similarity to $14-3-$ 3 is only structural, as the positively charged phosphate-binding pocket in 14-3-3 is not conserved in Ge-1.

\section{The C-terminal region of $D$. melanogaster $\mathrm{Ge}-1$ remains monomeric in solution}

In the crystal form we obtained, the two Ge- $1_{\mathrm{C}}$ molecules in the asymmetric unit dimerize in a head-to-tail fashion (Fig. $2 \mathrm{C})$. The dimerization interface is extensive, burying $13 \%$ of the surface of each monomer $\left(932 \AA^{2}\right.$ of surface area buried out of $\left.7416 \AA^{2}\right)$, as calculated using the PISA server (Krissinel and Henrick 2007). The helices $\alpha 1$ and $\alpha 2$ of one polypeptide chain contact helices $\alpha 5$ and $\alpha 7$ of the other polypeptide (Fig. all residues in the electron density are well ordered, while the other molecule, B, contains a disordered region (residues 1256-1265). In both chains, the peptide sequence Gly-AlaMet-Gly precedes the residue Asp1220 and is derived from the expression vector; this sequence is ordered and forms an additional turn at the start of the $\mathrm{N}$-terminal $\alpha$-helix.

\section{The C-terminal region of Ge-1 is constructed of $\alpha$-helical hairpin repeats}

The crystal structure of Ge- $1_{\mathrm{C}}$ (residues 1220-1354) consists of seven $\alpha$-helices $(\alpha 1-3$ and $\alpha 5-8)$ arranged in helix-turn-helix hairpins (Fig. 2A). The tandem stacking of the helical motifs gives rise to a superhelical architecture with an overall right-handed twist. The regular packing of the hairpins is interrupted by a short $\alpha$-helical insert in the second hairpin repeat $(\alpha 4)$, producing a marked kink in the molecule. The $\alpha 4$ insertion is disordered in one of the two molecules in the asymmetric unit (molecule B), suggesting conformational flexibility.

A search of the Protein Data Bank using the DALI server (Holm and Sander 1995) revealed that the superhelical architecture of $\mathrm{Ge}-1_{\mathrm{C}}$ is similar to proteins composed of right-handed $\alpha$-helical repeats, such as armadillo (ARM) repeat and Huntington-elongation-A-subunit-TOR (HEAT) repeat proteins. The closest structural homologs include,
2C). The central portion of the dimer interface involves van der Waals contacts between Leu1240 of one monomer and a hydrophobic pocket lined with the side chains of Leu1239, Leu1240, and His1236 within the other monomer (Figs. 2C, 1B). Water molecules mediate interchain hydrogenbonding interactions between the backbone of Leu1239 and Leu1240 and the side chains of Ser1274, Gln1277, Gln1278, and His1311. Several of these amino acid residues are evolutionarily conserved. In particular, Leu1239, Ser1274, and Gln1278 are invariant (Fig. 1B), and Gln1277 and His1311 are present in most Ge-1 orthologs (except in Caenorhabditis elegans).

The extents of both the dimerization interface observed in the crystals and the conservation of the residues mediating this self-association suggest a physiological dimer. Therefore we analyzed the behavior of $\mathrm{Ge}-1_{\mathrm{C}}$ in solution by coupling size exclusion chromatography (Superdex 200 column) to a static light scattering device (Viscotek). We found that Ge- $1_{\mathrm{C}}$ elutes as a single peak of $\sim 18 \mathrm{kDa}$ molecular weight and with monodispersity of less than 1.010 (Supplemental Figure 1 ), indicating that $D$. melanogaster $\mathrm{Ge}-1_{\mathrm{C}}$ remains monomeric in solution. Nevertheless, it is possible that Ge-1 $1_{C}$ contributes to self-association in the context of the entire Cterminal domain. Indeed, the entire C-terminal domain (residues 944-1354) oligomerizes in solution (data not shown). In agreement with this, self-association was also 

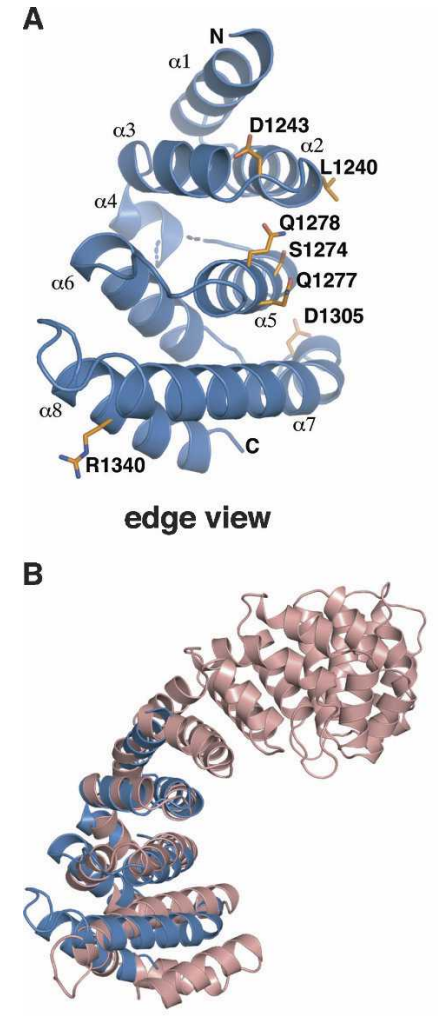

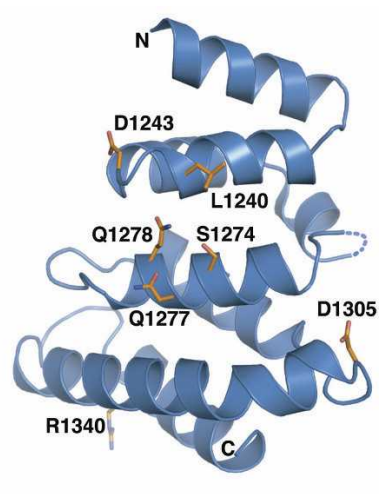

front view

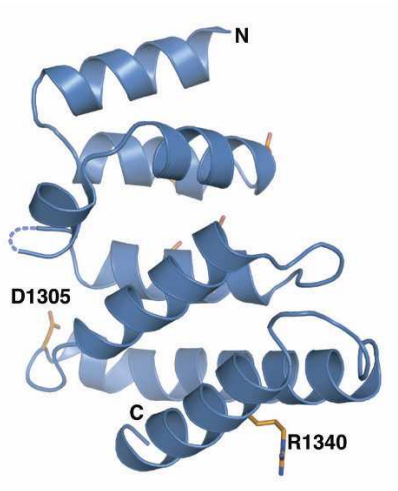

back view

c

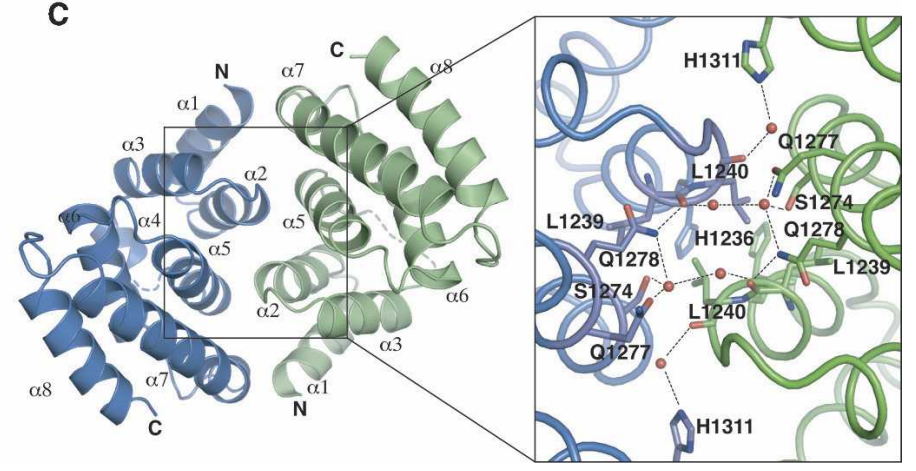

FIGURE 2. The C-terminal region of Ge-1 adopts a helical-repeat fold similar to that of ARM/HEAT repeat proteins. (A) Ribbon diagram of $\mathrm{Ge}-1_{\mathrm{C}}$ in three orientations related by a $90^{\circ}$ rotation around a vertical axis. Disordered portions of the polypeptide chains are indicated with dashed lines. Conserved residues discussed in the text are highlighted as sticks. All ribbon diagrams were generated using Pymol (http://www.pymol.org). (B) Structural superpositions of the Ge-1 C-terminal domain (colored blue) with the helical-repeat protein importin- $\alpha$ (colored pink, PDB entry 1ee5). The molecules are viewed as in the left panel of $A$. (C) Ge-1 crystallographic dimer viewed down the noncrystallographic twofold axis, with the two polypeptide chains in the asymmetric unit colored in blue and green respectively. The close-up shows the residues at the interface, with water molecules shown as red spheres. Hydrogen-bonding interactions are indicated with black dashed lines.

observed with the entire C-terminal domain of A. thaliana Ge-1 (Xu et al. 2006).

\section{Functional analysis of conserved surface residues in $\mathrm{Ge}-\mathbf{1}_{\mathrm{C}}$}

Mapping amino acid conservation onto the molecular surface of $\mathrm{Ge}-1_{\mathrm{C}}$ reveals several conserved surface residues in addition to Ser1274 and Gln1278 discussed above (Figs. 2A, 3). The invariant Asp1305 caps the $\mathrm{N}$ terminus of helix $\alpha 7$ and may therefore be conserved for structural reasons, to stabilize the helix dipole (Figs. 1B, 2A, 3). Similarly, Asp1243 caps the $\mathrm{N}$ terminus of helix $\alpha 3$ (Figs. 1B, 2A, 3). In contrast, Ser1274, Glu1277, Glu1278 (helix $\alpha 5$ ), and Arg1340 on the solvent-exposed surface of helix $\alpha 8$ are unlikely to be conserved for structural reasons (Figs. 1B, $2 \mathrm{~A}, 3)$. We therefore tested whether the conservation of these residues might be important for functional reasons. To this end, Ser1274 and Glu1277, which form a conserved patch on the crystal packing interface of $\mathrm{Ge}-1_{\mathrm{C}}$, were each substituted by a large positively charged residue (Arg). We also substituted Arg1340, located on the opposite side of the molecule, with glutamic acid (R1340E). We examined the effect of these mutations on DCP1 and DCP2 binding as well as on P-body localization in the context of the fulllength protein.

To test the interaction with DCP1 and DCP2, we coexpressed GFP fusions of these proteins with HA-tagged Ge-1 wild type or mutants and assayed whether they could be coimmunoprecipitated from cell lysates using anti-HA antibodies. An HA-tagged version of maltose binding protein (HA-MBP) served as a negative control. We found that both GFP-DCP1 and GFP-DCP2 coimmunoprecipitated with full-length $\mathrm{HA}-\mathrm{Ge}-1$, as well as with the proteins carrying the amino acid substitutions described above (Fig. $4 \mathrm{~A}$, lanes 10-12,14-16, respectively), indicating that the conserved residues are not critical for these interactions. This is consistent with the report that the corresponding Ge- $1_{C}$ fragment is dispensable for interactions with DCP1 and DCP2 in A. thaliana (Xu et al. 2006). Instead, the upstream less conserved part of the C-terminal domain interacted with both DCP2 and DCP1, although the interaction with DCP1 was less efficient than that with full-length Ge-1 (Xu et al. 2006). 

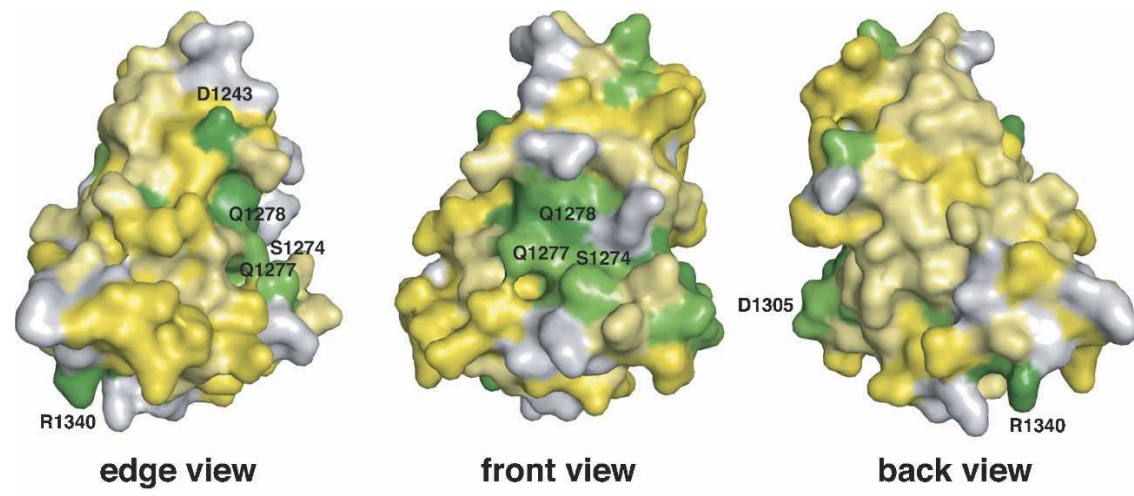

$0 \%$

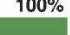

FIGURE 3. Identification of conserved molecular surfaces of Ge-1 $1_{\mathrm{C}}$. (A) Surface conservation within $\mathrm{Ge}-1_{\mathrm{C}}$ in the same orientations as in Figure $2 \mathrm{~A}$. The colors range from green for invariant residues to white for nonconserved residues. The representation was generated based on the sequence alignment shown in Figure 1B using the ConSurf server (Landau et al. 2005).

Although we do not know whether the interaction of Ge-1 with DCP1 or DCP2 is direct or mediated by additional proteins, we can rule out the possibility that under our experimental conditions we are coimmunoprecipitating large protein aggregates (e.g., submicroscopic P-bodies), because under these conditions we could not detect an association between Ge-1 and additional P-body components including Me31B, EDC3, or HPat (Fig. 4B; data not shown). As a positive control, Me31B coimmunoprecipitated with HA-EDC3 as reported before (Fig. 4B; Tritschler et al. 2007).

We next tested the effect of the substitutions on P-body localization. As reported before, we found that GFP-tagged Ge-1 accumulated in cytoplasmic foci (Eulalio et al. 2007 b,c), which correspond to endogenous P-bodies as judged by the staining with antibodies to Tral (Trailer Hitch, a P-body marker in D. melanogaster; Fig. 4C; Eulalio et al. 2007 a,b). In contrast, a GFP-tagged protein carrying the R1340E substitution distributed diffusely throughout the cytoplasm and formed fewer GFP foci in a subset of cells (Fig. 4C). To quantify this effect the number of cells displaying GFP foci was counted. Whereas more than $90 \%$ of cells expressing wild-type GFP-Ge1 displayed GFP foci (Fig. 4C), only $62 \%$ of cells expressing the R1340E mutant displayed GFP foci, which were reduced in number. Note that the number and size of endogenous P-bodies was not affected in these cells (Fig. 4C). Moreover, $\sim 31 \%$ of cells expressing the mutant protein had no detectable GFP foci (Fig. 4C).

The expression of the R1340E mutant was comparable to that of the wild type (Fig. 4A), suggesting that the substitution has no significant effect on the general folding or stability of Ge-1. The effect of this mutation appears to be specific, as substitutions of the conserved residues Ser1274 or Gln1277 (S1274R, Q1277R) did not affect the accumulation of the protein into endogenous P-bodies (Fig. 4C). Moreover, because the R1340E substitution does not affect the interaction between Ge-1and DCP1 or DCP2, we conclude that these interactions are not sufficient to direct $\mathrm{Ge}-1$ to P-bodies. Together our results argue that the highly conserved C-terminal region of Ge-1 has an essential role in promoting its accumulation in P-bodies.

\section{Conclusions}

The C-terminal highly conserved region of Ge-1 consists of tandem $\alpha$-helical repeats. We crystallized a protein fragment in which the first four $\mathrm{N}$-terminal residues were encoded by the expression vector. These $\mathrm{N}$-terminal amino acids are well ordered and form part of the Nterminal $\alpha$-helix of $\mathrm{Ge}-1_{\mathrm{C}}$, suggesting that the truncated construct we crystallized interrupts an element of secondary structure that is likely completed by a few amino acid residues in the native sequence. It is possible that the whole C-terminal domain, including the less conserved region, consists of $\alpha$-helical hairpins, which stack to form an elongated molecule, somewhat similar to other elongated $\alpha$-helical repeat proteins (Jinek et al. 2004; Conti et al. 2006). Such proteins are typically scaffolds, whose surface mediates interactions with other macromolecules.

In the case of Ge-1, the surface centered at Arg1340 is critical for P-body localization, suggesting that interactions with other P-body component(s) drive Ge-1 into P-bodies. Given the evolutionary conservation of this residue, this localization mechanism is likely to be conserved across species. A spatially distinct and evolutionary conserved surface, centered at Ser1274, Gln1277, and Gln1278, is involved in crystal packing. This surface may contribute to Ge-1 self-association in vivo or may represent a site where other P-body components, distinct from DCP1 or DCP2, interact.

Ge-1 is an essential P-body component in D. melanogaster and human cells, as when it is depleted the remaining Pbody components disperse throughout the cytoplasm (Yu et al. 2005; Eulalio et al. 2007 b,c). Like many P-body proteins, Ge-1 has a modular domain organization. Such modularity may enable Ge-1 to interact with multiple Pbody components simultaneously, bringing them into close proximity and thereby facilitating P-body assembly.

\section{MATERIALS AND METHODS}

\section{Protein expression, purification, and crystallization}

The C-terminal region of D. melanogaster Ge-1 (Swissprot entry Q9VKK1, residues 1220-1354) was subcloned into a pET-derived expression vector, in frame with the NusA protein, a hexahistidine 
affinity tag, and a TEV protease cleavage sequence. The resulting fusion protein was expressed in the Escherichia coli strain BL21 Gold (Stratagene) at $20^{\circ} \mathrm{C}$ by inducing with $0.5 \mathrm{mM}$ IPTG for $16 \mathrm{~h}$. Cells were lysed by sonication in $50 \mathrm{mM}$ sodium phosphate buffer ( $\mathrm{pH} 8.0$ ), $300 \mathrm{mM} \mathrm{NaCl}, 20 \mathrm{mM}$ imidazole, $2 \mathrm{mM} \beta$ mercaptoethanol. The protein was purified by affinity chromatography using $\mathrm{Ni}^{2+}$-NTA agarose (Qiagen) and cleaved with TEV protease. The released affinity tag was removed by a subtractive $\mathrm{Ni}^{2+}$-affinity step. The protein was further purified by sizeexclusion chromatography in $50 \mathrm{mM}$ Tris- $\mathrm{Cl}$ (pH 7.5), $150 \mathrm{mM}$ $\mathrm{NaCl}, 1 \mathrm{mM}$ DTT, and concentrated to $\sim 4 \mathrm{mg} \mathrm{mL}^{-1}$. Needle-like crystals of Ge-1 were grown at $18^{\circ} \mathrm{C}$ using the sitting-drop vapor diffusion method by mixing $2 \mu \mathrm{L}$ of protein solution with $1 \mu \mathrm{L}$ of reservoir solution containing $100 \mathrm{mM}$ Tris- $\mathrm{Cl}(\mathrm{pH}$ 8.2) and 20\%-30\% (w/v) PEG 3350. Selenomethionine-substituted Ge-1 was expressed in the E. coli strain DL41, purified as the native protein, and crystallized in $100 \mathrm{mM}$ Tris- $\mathrm{Cl}(\mathrm{pH} 8.2)$ and $21 \%(\mathrm{w} / \mathrm{v})$ PEG 3350.

\section{Structure determination}

For data collection at $100 \mathrm{~K}$, native and selenomethioninesubstituted crystals were soaked briefly in $100 \mathrm{mM}$ Tris $(\mathrm{pH}$ 8.2), 20\% (w/v) PEG 3350, 20\% (v/v) PEG 400, and flash-cooled in liquid nitrogen. Both native and selenomethionine singlewavelength anomalous dispersion (SAD) data (measured at the Se K-absorption wavelength $0.97897 \AA$ ) were collected at beamline X06SA of the Swiss Light Source (Villigen, Switzerland) and processed with XDS (Kabsch 1993). Seven selenium sites were located using the Hybrid Structure Search (HySS) module of the PHENIX package (Grosse-Kunstleve and Adams 2003). Substructure refinement, phasing, and density modification were performed using AutoSHARP (Bricogne et al. 2003), yielding an initial electron density map revealing two polypeptide chains in the asymmetric unit. This was followed by noncrystallographic twofold symmetry averaging, phase extension, and initial automated chain tracing using RESOLVE (Terwilliger 2003). The atomic model was completed by automated model building in ARP/wARP and subsequent iterative cycles of manual model building in COOT (Emsley and Cowtan 2004) and TLS refinement in REFMAC5 (Murshudov et al. 1997) against the high-resolution native data set. The final atomic model has been refined to a free- $R$ factor of $25.4 \%$ and a working- $R$ factor of $21.1 \%$, with good stereochemistry (Table 1), and contains two polypeptide chains in the asymmetric unit. Chain A comprises residues 1220-1350, with the exception of residues 1262-1265, for which no electron density is observed. Chain B consists of residues 1220-1255 and 1266-1353, with the residues 1256-1265 disordered.

\section{Transfection of S2 cells and fluorescence microscopy}

cDNAs encoding full-length EDC3, Me31B, DCP1, DCP2, and Ge-1 were described before (Eulalio et al. 2007 b,c). Mutants of D. melanogaster Ge-1 were generated by site-directed mutagenesis using the Quick Change mutagenesis kit from Stratagene and the appropriate oligonucleotide sequences. All constructs were fully sequenced to confirm the presence of the mutations and the absence of additional mutations.

Transfections were performed in six-well dishes using Effectene transfection reagent (Qiagen). Three days after transfection,

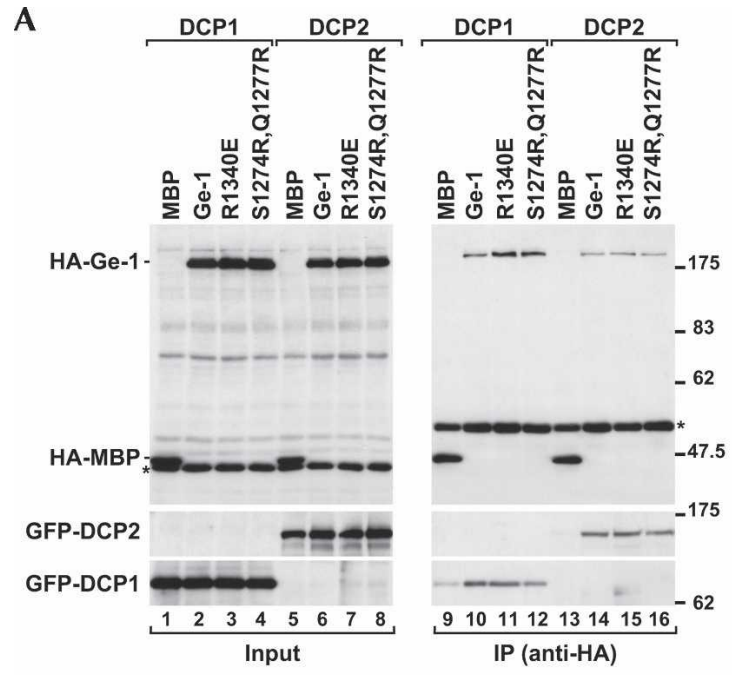

B
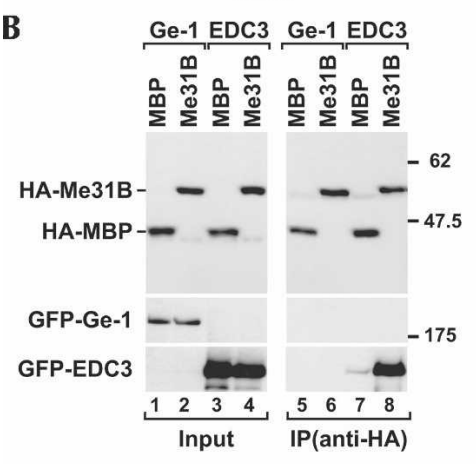

C
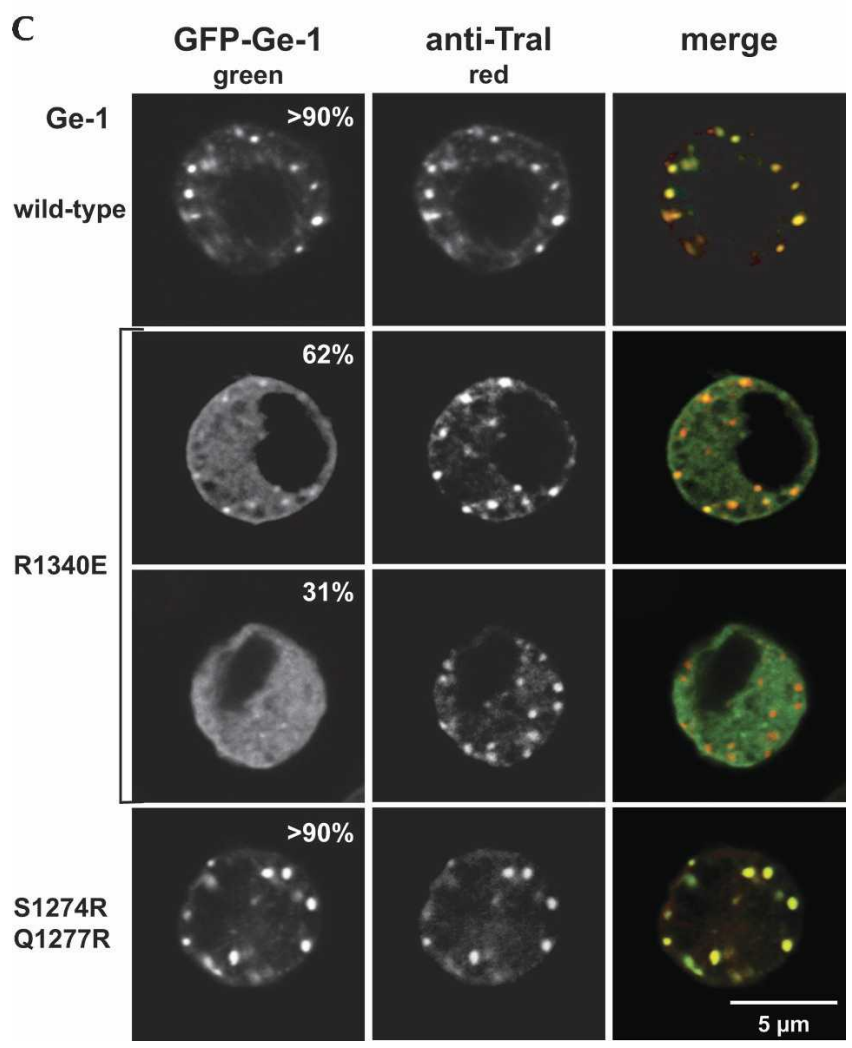

FIGURE 4. (Legend on next page) 
S2 cells were allowed $15 \mathrm{~min}$ to adhere to poly-D-Lysinecoated coverslips, washed once in serum-free medium, and fixed with $4 \%$ paraformaldehyde in PBS for $15 \mathrm{~min}$, followed by $5 \mathrm{~min}$ incubation in methanol at $-20^{\circ} \mathrm{C}$. After fixation, cells were washed in PBS, permeabilized for $5 \mathrm{~min}$ with PBS containing $0.5 \%$ Triton X-100, and washed again with PBS. Cells were stained with affinity purified anti-Tral antibodies (Eulalio et al. 2007 b,c) diluted 1:250 in PBS containing $1 \%$ BSA. TRITC-coupled goat secondary antibody (Molecular Probes) was used in a dilution of 1:250. Cells were mounted using Fluoromount-G (Southern Biotechnology Associates, Inc.). Images were acquired using a Leica TCS SP2 confocal microscope.

\section{Coimmunoprecipitation assays and Western blotting}

For coimmunoprecipitations, S2 cells were collected $3 \mathrm{~d}$ after transfection, washed with PBS, and resuspended in NET buffer (50 mM Tris at $\mathrm{pH} 7.4,150 \mathrm{mM} \mathrm{NaCl}, 1 \mathrm{mM}$ EDTA, 0.1\% Triton $\mathrm{X}-100)$ supplemented with protease inhibitors. Cells were lysed by three 30 -sec sonication treatments, followed by 15 min incubation on ice. Cells were spun at $16,000 \mathrm{~g}$ for $15 \mathrm{~min}$ at $4^{\circ} \mathrm{C}$. Anti-HA antibodies (Covance Research Products) were added to the supernatants $\left(2.5 \mu \mathrm{L} / 2 \times 10^{6}\right.$ cells $)$. After $1 \mathrm{~h}$ at $4^{\circ} \mathrm{C}, 25 \mu \mathrm{L}$ of Protein G-agarose (Roche) were added and the mixtures were rotated $1 \mathrm{~h}$ at $4^{\circ} \mathrm{C}$. Beads were washed three times with NET buffer and once with NET buffer without Triton X-100. Bound proteins were eluted with sample buffer.

Proteins were separated by SDS-PAGE and transferred to nitrocellulose membranes. Membranes were blocked in PBS containing $5 \%$ fat-free milk powder and $0.3 \%$ Tween-20. Western blotting was performed with polyclonal anti-HA antibodies (1:1000; Sigma; catalog number H6908) and anti-GFP antibodies (1:2000), using the CDP-Star chemiluminescent immunoblot system (Western-Star kit from Tropix), as recommended by the manufacturer.

FIGURE 4. Functional analysis of conserved molecular surfaces of Ge-1. (A) HA-tagged maltose binding protein (MBP), Ge-1 wild type or the indicated Ge-1 mutants were cotransfected in S2 cells with GFP-DCP1 or GFP-DCP2, as indicated. Cell lysates were immunoprecipitated using a monoclonal anti-HA antibody. HA-MBP served as a negative control. Inputs (1.25\%) and immunoprecipitates $(30 \%)$ were analyzed by Western blotting using polyclonal anti-HA and antiGFP antibodies. Asterisks indicate cross-reactivity of the polyclonal anti-HA antibody with an endogenous protein (input panels) or cross-reactivity with the immunoglobulin heavy chain by the secondary antibody (IP panels). (B) HA-tagged MBP or Me31B were cotransfected in S2 cells with GFP-Ge-1 or GFP-EDC3. Cell lysates were immunoprecipitated using a monoclonal anti-HA antibody. Inputs $(1.25 \%)$ and immunoprecipitates $(30 \%)$ were analyzed by Western blotting using polyclonal anti-HA and anti-GFP antibodies. (C) Confocal fluorescent micrographs of fixed S2 cells expressing GFP-fusions of full length Ge-1 (wild-type, wt) or mutant proteins. Cells were stained with affinity-purified anti-Tral antibodies. The fraction of cells exhibiting a staining identical to that shown in the representative panel was determined by scoring at least 100 cells in two independent transfections performed per protein. The merged images show the GFP signal in green and the Tral signal in red. Scale bar: $5 \mu \mathrm{m}$.

\section{Data deposition}

The atomic coordinates and structure factors for D. melanogaster Ge- $1_{C}$ have been deposited in the Protein Data Bank (PDB) under access code $2 \mathrm{VXG}$.

\section{SUPPLEMENTAL DATA}

Supplemental material can be found at http://www.rnajournal.org.

\section{ACKNOWLEDGMENTS}

We are grateful to J. Basquin, A. Cook, and A. Scholz for help with crystallization screens and to C. Basquin and J. Tittor for static light scattering experiments. We thank C. Schulze-Briese and the staff at the PX beamlines of the Swiss Light Source for assistance with data collection. This study was supported by the Max Planck Society and by a grant from the Deutsche Forschungsgemeinschaft (DFG, FOR855).

Received June 13, 2008; accepted July 7, 2008.

\section{REFERENCES}

Bail, S. and Kiledjian, M. 2006. More than $1+2$ in mRNA decapping. Nat. Struct. Mol. Biol. 13: 7-9.

Bricogne, G., Vonrhein, C., Flensburg, C., Schiltz, M., and Paciorek, W. 2003. Generation, representation and flow of phase information in structure determination: Recent developments in and around SHARP 2.0. Acta Crystallogr. D Biol. Crystallogr. 59: 2023-2030.

Conti, E. and Kuriyan, J. 2000. Crystallographic analysis of the specific yet versatile recognition of distinct nuclear localization signals by karyopherin $\alpha$. Structure 8: 329-338.

Conti, E., Müller, C.W., and Stewart, M. 2006. Karyopherin flexibility in nucleocytoplasmic transport. Curr. Opin. Struct. Biol. 16: 237244.

Deyholos, M.K., Cavaness, G.F., Hall, B., King, E., Punwani, J., Van Norman, J., and Sieburth, L.E. 2003. VARICOSE, a WD-domain protein, is required for leaf blade development. Development 130: 6577-6588.

Emsley, P. and Cowtan, K. 2004. Coot: Model-building tools for molecular graphics. Acta Crystallogr. D Biol. Crystallogr. 60: 21262132.

Eulalio, A., Behm-Ansmant, I., and Izaurralde, E. 2007a. P bodies: At the crossroads of post-transcriptional pathways. Nat. Rev. Mol. Cell Biol. 8: 9-22.

Eulalio, A., Behm-Ansmant, I., Schweizer, D., and Izaurralde, E. 2007b. P-body formation is a consequence, not the cause of RNAmediated gene silencing. Mol. Cell. Biol. 27: 3970-3981.

Eulalio, A., Rehwinkel, J., Stricker, M., Huntzinger, E., Yang, S.-F., Doerks, T., Dorner, S., Bork, P., Boutros, M., and Izaurralde, E. 2007c. A target-specific requirement for enhancers of decapping in miRNA-mediated gene silencing. Genes \& Dev. 21: 25582570.

Fenger-Grøn, M., Fillman, C., Norrild, B., and Lykke-Andersen, J. 2005. Multiple processing body factors and the ARE binding protein TTP activate mRNA decapping. Mol. Cell 20: 905-915.

Grosse-Kunstleve, R.W. and Adams, P.D. 2003. Substructure search procedures for macromolecular structures. Acta Crystallogr. D Biol. Crystallogr. 59: 1966-1973.

Holm, L. and Sander, C. 1995. Dali: A network tool for protein structure comparison. Trends Biochem. Sci. 20: 478-480.

Houseley, J., LaCava, J., and Tollervey, D. 2006. RNA-quality control by the exosome. Nat. Rev. Mol. Cell Biol. 7: 529-539. 
Jinek, M., Rehwinkel, J., Lazarus, B.D., Izaurralde, E., Hanover, J.A., and Conti, E. 2004. The superhelical TPR-repeat domain of O-linked GlcNAc transferase exhibits structural similarities to importin $\alpha$. Nat. Struct. Mol. Biol. 11: 1001-1007.

Kabsch, W. 1993. Automatic processing of rotation diffraction data from crystals of initially unknown symmetry and cell constants. J. Appl. Crystallogr. 26: 795-800.

Krissinel, E. and Henrick, K. 2007. Inference of macromolecular assemblies from crystalline state. J. Mol. Biol. 372: 774-797.

Landau, M., Mayrose, I., Rosenberg, Y., Glaser, F., Martz, E., Pupko, T., and Ben-Tal, N. 2005. ConSurf 2005: The projection of evolutionary conservation scores of residues on protein structures. Nucleic Acids Res. 33: W299-W302.

Marcotrigiano, J., Lomakin, I.B., Sonenberg, N., Pestova, T.V., Hellen, C.U., and Burley, S.K. 2001. A conserved HEAT domain within eIF4G directs assembly of the translation initiation machinery. Mol. Cell 7: 193-203.

Murshudov, G.N., Vagin, A.A., and Dodson, E.J. 1997. Refinement of macromolecular structures by the maximum-likelihood method. Acta Crystallogr. D Biol. Crystallogr. 53: 240-255.

Parker, R. and Sheth, U. 2007. P bodies and the control of mRNA translation and degradation. Mol. Cell 25: 635-646.

Parker, R. and Song, H. 2004. The enzymes and control of eukaryotic mRNA turnover. Nat. Struct. Mol. Biol. 11: 121-127.

Rittinger, K., Budman, J., Xu, J., Volinia, S., Cantley, L.C., Smerdon, S.J., Gamblin, S.J., and Yaffe, M.B. 1999. Structural analysis of 14-3-3 phosphopeptide complexes identifies a dual role for the nuclear export signal of 14-3-3 in ligand binding. Mol. Cell 4: 153-166.

She, M., Decker, C.J., Sundramurthy, K., Liu, Y., Chen, N., Parker, R., and Song, H. 2004. Crystal structure of Dcplp and its functional implications in mRNA decapping. Nat. Struct. Mol. Biol. 11: 249256.

She, M., Decker, C.J., Chen, N., Tumati, S., Parker, R., and Song, H. 2006. Crystal structure and functional analysis of Dcp2p from Schizosaccharomyces pombe. Nat. Struct. Mol. Biol. 13: 63-70.

She, M., Decker, C.J., Svergun, D.I., Round, A., Chen, N., Muhlrad, D., Parker, R., and Song, H. 2008. Structural basis of dcp2 recognition and activation by dcp1. Mol. Cell 29: 337-349.

Simon, E., Camier, S., and Séraphin, B. 2006. New insights into the control of mRNA decapping. Trends Biochem. Sci. 31: 241-243.

Terwilliger, T.C. 2003. SOLVE and RESOLVE: Automated structure solution and density modification. Methods Enzymol. 374: 22-37.

Tritschler, F., Eulalio, A., Truffault, V., Hartmann, M.D., Helms, S., Schmidt, S., Coles, M., Izaurralde, E., and Weichenrieder, O. 2007. A divergent Sm-fold in EDC3 proteins mediates DCP1-binding and P-body targeting. Mol. Cell. Biol. 27: 8600-8611.

Xu, J., Yang, J.Y., Niu, Q.W., and Chua, N.H. 2006. Arabidopsis DCP2, DCP1, and VARICOSE form a decapping complex required for postembryonic development. Plant Cell 18: 33863398.

Yu, J.H., Yang, W.H., Gulick, T., Bloch, K.D., and Bloch, D.B. 2005. Ge-1 is a central component of the mammalian cytoplasmic mRNA processing body. RNA 11: 1795-1802. 

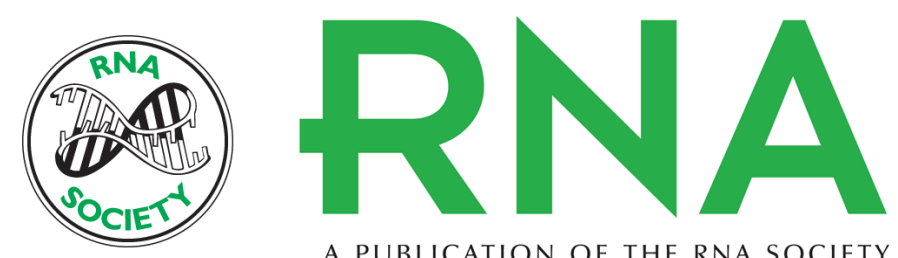

A PUBLICATION OF THE RNA SOCIETY

\section{The C-terminal region of Ge-1 presents conserved structural features required for P-body localization}

Martin Jinek, Ana Eulalio, Andreas Lingel, et al.

RNA 2008 14: 1991-1998 originally published online August 28, 2008

Access the most recent version at doi:10.1261/rna.1222908

Supplemental
Material http://rnajournal.cshlp.org/content/suppl/2008/08/29/rna.1222908.DC1

References This article cites 30 articles, 6 of which can be accessed free at:

http://rnajournal.cshlp.org/content/14/10/1991.full.html\#ref-list-1

\section{License}

Email Alerting Receive free email alerts when new articles cite this article - sign up in the box at the Service top right corner of the article or click here. 